\title{
Right Atrial Thrombosis associated with Sagittal Sinus Thrombosis caused by Protein C-S Deficiency
}

\author{
Feridoun Sabzi, ${ }^{1}$ Reza Faraji' \\ 'Department of Cardiovascular Surgery, Imam Ali Heart Center, Kermanshah University of Medical Sciences, Kermanshah, \\ Iran.
}

\section{ABSTRACT}

Right atrial thrombi may develop within the right atrium or may have peripheral venous origins that, on their way to the final destination site lodge in, right atrium. Right atrial thrombosis is classified as two type: A (mobile, thin) and B (non mobile and attached to atrial wall) that they are probably of cardiac origin due to local pathology, indwelling catheter, atrial fibrillation, stasis, rheumatological or hematological disease like protein $\mathrm{C}$ or $\mathrm{S}$ deficiency. Protein $\mathrm{C}$ deficiency has been reported to be a risk factor for thrombosis in multiple organs as a result of inactivation of factor of $\mathrm{Va}$. We describe a case of a huge right atrial thrombus with cerebral sagittal sinus thrombosis, in a protein C-S deficient patient, in which right atrial clot was successfully removed surgically and sagittal vein treated conservatively with full recovery of his central neurologic symptom. Magnetic Resonance Imaging demonstrated thrombosis in those regions.

Keywords: protein C-S; right atrium; sagittal sinus.

\section{INTRODUCTION}

Protein C-S deficiency is genetic traits predisposing to the formation of thrombosis in venous system. ${ }^{1}$ It was originally thought that protein $\mathrm{C}$ deficiency might actually predispose to thrombosis, possibly as the result of deficient activation of fibrinolysis but protein $\mathrm{C}$ relates to multiple processes involving anticoagulation, system. Sagittal sinus thrombosis can be caused by a wide range of etiologies, including hypercoagulable disorders, such as factor $\mathrm{V}$ Leiden mutation, presence of anticardiolipin antibody, antithrombin gene mutation, polycythemia and protein C-S deficiency and hypercysteinemia. ${ }^{2}$ This report a protein C-S deficient patient who had concomitant a right atrial giant thrombus with sagittal sinus thrombosis.

\section{CASE REPORT}

A 26-year-old man was referred to our hospital with a 2-week history of dyspnea, sever occipital headache, ear complaint and nausea without focal neurological abnormalities and seizures. On admission, physical examination revealed a heart rate of 110 per minute, regular; blood pressure of $120 / 70 \mathrm{mmHg}$; and respiratory rate of 20 per minute. On cardiac auscultation, a normal first heart sound without murmur and diastolic rumble was audible at the apex. An electrocardiogram demonstrated sinus tachycardia. Complete blood count and blood biochemistry were within normal limits, except for prolonged erythrocyte sedimentation and a reduced protein $\mathrm{C}$ and $\mathrm{S}$ level. The protein $\mathrm{C}$ level was $45 \%$ (normal $>70 \%$ ) and protein $S$ level was $55 \%$ (normal $65 \%$ ) There are no abnormal values of antithrombin III, lupus anticoagulant, and anticardiolipin

Correspondence: Reza Faraji, Kermanshah University of Medical Sciences, Kermanshah, Iran. Email: rezafaraji $60 @ y$ ahoo. com, Phone: + 988318360295 . 
antibodies, HLA-B5, HLA-B27, anti-nuclear antibody and rheumatoid factor were negative. Ophthalmological examination showed no significant finding. A transthoracic two-dimensional echocardiogram of the right atrium demonstrated a giant thrombus with a fixed clot in the apical four-chamber view (Figure 1).

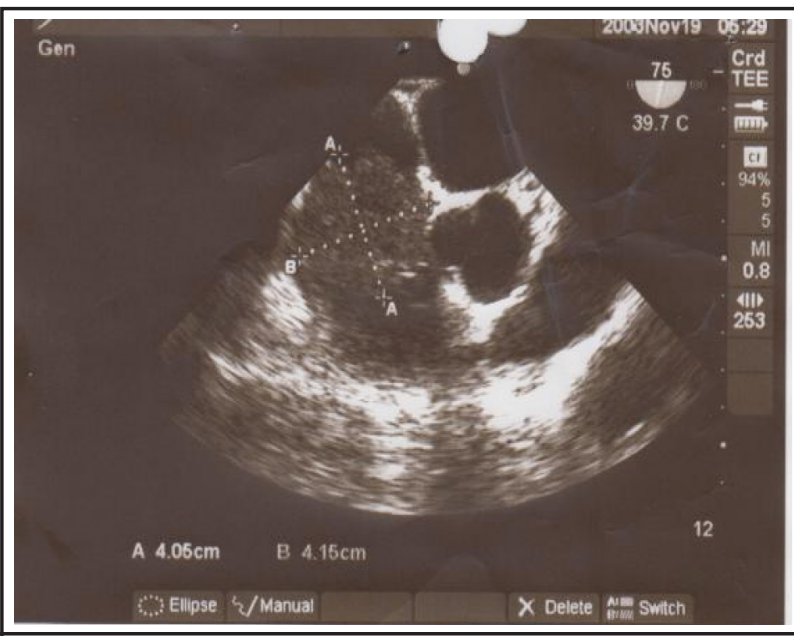

Figure 1. Transthoracic two-dimensional echocardiogram of the right atrium showing a huge thrombus with fixed clot.

The diameters of thrombus were measured as 4.05 $x 4.15 \mathrm{~cm}$. Pathologic examination of the atrial mass revealed an organized thrombus. The right atrium was not dilated and tricuspid valve was normal without regurgitation or stenosis. There was also a small amount of pericardial fluid collection. Brain C-T scan and MRI revealed sagittal venous system thrombosis (Figure 2).

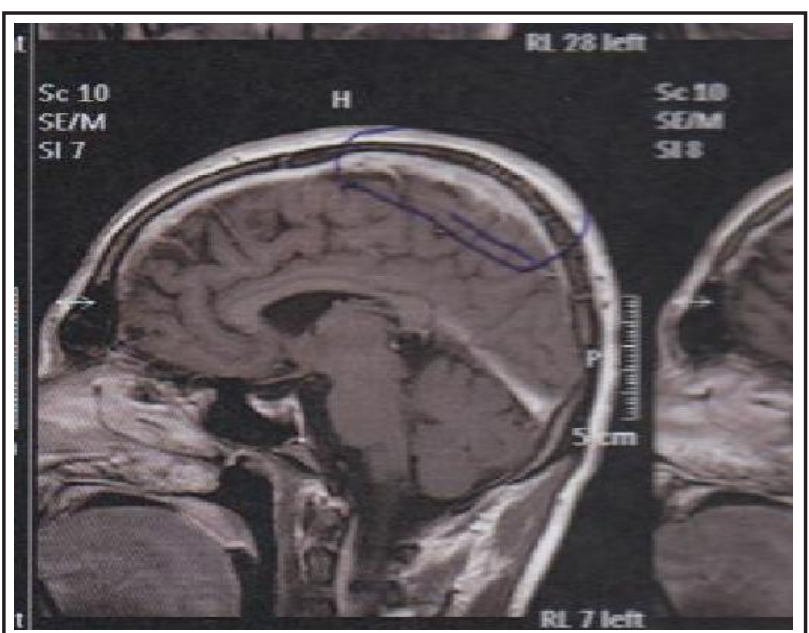

Figure 2. Sagittal gadolinium-enhanced T1-weighted image shows extensive filling defects in superior sagittal sinus.

In our knowledge, this is the first reported case of right atrial thrombosis associated with protein C-S deficiency and sagittal sinus thrombosis. Cardiopulmonary bypass was instituted by standard ascending aorta and bicavalcannulation with moderate systemic hypothermia. Through a right atriotomy, an old and huge thrombus was found to fill within appendage of the right atrium and continued to Inferior venacava (IVC) orifice that was removed successfully. There was no any structural abnormally in right atrium, Ebstien disease or atrial fibrillation or atrial septal defect. Postoperative course was satisfactory. Postoperative oral anticoagulation therapy was started with warfarin sodium, with a target international normalized ratio of thrombo test between 2 and 2.5. An antiplatelet regimen of Clopidogrel (75 mg per day) was added (Figure 3). He was discharged on the 10th postoperative day.

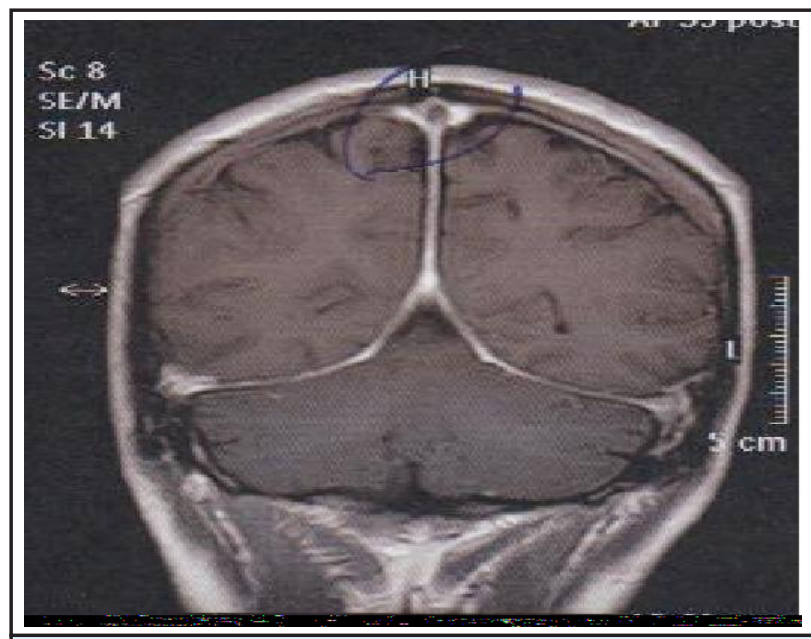

Figure 3. Coronal gadolinium enhanced T1-weighted image represents thrombosis of superior sagittal sinus. Note filling defect of thrombus, giving rise to empty delta sign.

\section{DISCUSSION}

Virchow identified hyper coagulability as a predisposing factor for thrombosis over 140 years ago, but until recently an abnormality affecting coagulation could be pinpointed in only a small minority of patients with thrombosis. ${ }^{2}$ Marar described that Protein $\mathrm{C}$ is the central component of a major antithrombotic regulatory system with both anticoagulant and profibrinolytic properties. It inactivates factors $\mathrm{Va}$ and VIIla. Protein S is as a cofactor for these actions of Protein C. Protein C and Protein $\mathrm{S}$ deficiencies are genetic traits predisposing to the formation of venous clots. ${ }^{3}$ The hereditary protein C-S deficiency is a group of inherited conditions that predispose to thrombosis. Protein C-deficient patients usually develop venous thrombotic complications between the ages of 15 and 40 years with a high incidence of deep venous thrombosis and pulmonary embolism. ${ }^{4}$ In patients with protein C deficiency, thrombosis can also occur in the peripheral venous system, brain, retinal, mesenteric, renal veins and the 
inferior vena cava and portal vein. ${ }^{5}$ Most hereditary thrombotic lesions of protein C deficiency appear to develop spontaneously; or associated with trauma, surgery or pregnancy. Acquired Protein $\mathrm{C}$ and $\mathrm{S}$ deficiencies with consumption of protein $C$ occurred in patients with deep venous thrombosis, pulmonary embolism, acute disseminated intravascular coagulopathy, post-operative state, severe liver disease, malignancy, infection, hemolytic-uremic syndrome, adult respiratory distress syndrome and vitamin $\mathrm{K}$, primary myloproliferative disease, antiphospholipid antibody, paroxysmal nocturnal hemoglinopathy, contraceptive, childbirth, and hypercystinemia. ${ }^{6-9}$ Modestly elevated levels of plasma homocysteine, which are in part genetically determined, have also recently been associated with an increased risk for venous thromboembolism. Van Der Meer described that however heritable deficiencies of the endogenous anticoagulants protein $\mathrm{C}$, protein $\mathrm{S}$, and antithrombin have been recognized for decades but they are uncommon, even in patients with familial thrombosis. ${ }^{10}$ Dahlback discovered the resistance to activated protein C in $1993 .{ }^{11}$ Bertina described that this abnormality, caused by a point mutation in the factor $\mathrm{V}$ gene, ${ }^{12}$ that is much more common than all previously recognized forms of heritable thrombophilia, combined. Protein $\mathrm{C}$ is an endogenous anticoagulant protein that, in its activated form, cleaves and inactivates the activated forms of factors $V$ and VIII. The molecular defect responsible for activated protein $\mathrm{C}$ resistance was soon identified by investigators from Leiden, the Netherlands as a single point mutation in the factor $\mathrm{V}$ gene. ${ }^{13}$ This missense mutation causes an arginine to glutamine substitution in one of the protein's cleavage sites and renders activated factor $\mathrm{V}$ relatively resistant to cleavage, and thus inactivation, by activated protein $C$. This single genotype, factor $V$ Leiden, accounts for the phenotype of activated protein c resistance in nearly all cases. ${ }^{14}$ Allaart revealed that it is the most common cause of heritable thrombophilia. Heterozygous protein C-S deficiency has been associated with DVT, pulmonary thromboembolism, superficial venous thrombophlebitis and, rarely, arterial thrombosis. Some protein $\mathrm{C}-\mathrm{S}$ deficient heterozygotes remain asymptomatic. ${ }^{15}$ Prevalence of protein $\mathrm{C}$ antigen levels in adults in Miletich study was of $1: 200$ to $1: 300 .{ }^{16} \mathrm{In}$ contrast, protein $\mathrm{C}-\mathrm{S}$ deficient patients who have had a thromboembolic event have a comparatively greater risk for thrombosis, as do their family members. ${ }^{16}$ Allaart showed that by the age of 45 year, the heterozygous family members of a symptomatic patient with heterozygous protein $\mathrm{C}$ deficiency have a $50 \%$ chance of having thromboembolism. ${ }^{15}$ With half of these events associated with situations of increased clinical risk. Factor $\mathrm{V}$ Leiden deficiency has a high prevalence among symptomatic protein $\mathrm{C}$ deficient persons, and individuals who are heterozygous for both conditions have a more than two fold risk of thrombosis. Protein $S$ is a cofactor for activated protein $C .{ }^{17}$ The prevalence of protein $\mathrm{C}-\mathrm{S}$ deficiency in a large sample of unselected subjects has not been determined. Isolated cerebral venous thrombosis with protein C-S deficiency was reported inHIV, thyroid crisis, high altitude, presence of procoagulent factor, intra cranial hypertension, malignant brain edema, head injury, inflammatory bowel disease, typhoid fever, Henoch-Schonleinpurpura, uterine fibroma and, burn and iron deficiency anemia. ${ }^{18-30}$ The most of these patients after admission demonstrated generalized or local or subtle convulsions, stupor, hemiplegia, ear complaint, vomiting, headache. Cerebral angiography appeared to demonstrate complete obstruction of the superior sagittal sinus with congestion of venous flow in the cortical veins. Ulcerative colitis has been reported to show hyper coagulation, leading to deep vein thrombosis within the body which sometimes causes pulmonary infarction; however, occurrence of venous thrombosis in the intracranial veins and sinus is rare. In, thyrotoxicosis trigger was most likely thyroid crisis, suggesting that thyrotoxicosis, probably through hypercoagulability, may be a predisposing factor for the development of sagittal venous thrombosis. Bruhnin a case report described association between essential thrombocythemia and sagittal sinus thrombosis in non deficient protein $\mathrm{C}$ patient. These two previous cases were not associated with others organ thrombosis. ${ }^{31}$ Bruhn reported that in patients with a coagulation disorder, the overall incidenceof a thromboembolic event is increased when compared with thenormal population. The risk was reported to be eightfold inpatients with antithrombin deficiency, sevenfold in patientswith protein $\mathrm{C}$ deficiency, nine fold in patients with proteins deficiency, and twofold in patients with activated proteinC resistance. ${ }^{31}$ In Halbmayer study, Surgery and immobilization increased risk and trigger the occurrence of thromboembolicevents in otherwise healthy persons with thrombophilic diathesis. ${ }^{32}$ Indeed, Lodi showed that in patients with a thrombophilic diathesis, a predisposingfactor was reported to be present at the time of the thromboembolicevent in $50 \%$ of cases. ${ }^{33}$ Ratnoff described thromboembolicevents in patients with protein c deficiency incardiac surgery that include deep venous thrombosis, pulmonary embolism, graft occlusion, coagulation of the extracorporeal circuit, and others. Cardiac surgery for cardiac thrombi in conjunction withprotein $\mathrm{C}$ deficiency has been reported, but there is no surgicalreport of combined right atrial thrombus and sagittal venous thrombosis in a patient with protein $\mathrm{C}$ deficiency. ${ }^{34}$ Although a right atrial thrombus is usually coexistent with right atrial pathology and atrial fibrillation, other possible causes of thrombosissuch as systemic thrombogenic disease and 
coagulation disorder should be explored, especially in a patient with a huge atrial clot. Right atrial thrombus suggests that we should explore other possible causes of thrombosis suchas protein $\mathrm{C}$ deficiency. In a patient with protein $\mathrm{C}$ deficiency, appropriate anticoagulation therapy should be taken for prevention of the recurrence of thrombosis postoperatively. There is no clear consensus of the preferred treatment option for right atrial clot. Factors that have been considered include, type of clot, extent, size, shape, coexisting pulmonary emboli, and cardiopulmonary reserve. In general, patients with right atrial thrombosis who present with pulmonary emboli, or instability of hemodynamic, seems to better with thrombolytic therapy. ${ }^{35}$ As in patients with long, thin and snake like clot had high early mortality and have poor prognosis. The presence of huge right atrium clot without emboli need for rapid diagnosis and emergency operation. Thrombolytic therapies in these patients is efficient but expose the patient to risk of migration of intra atrial clot with occasionally deleterious evolution. In our patient, the diagnosis was delayed because of atypical presentation of symptoms and headache localized to occipital and mastoid area and because it was assumed that it was a case of acute mastoiditis. It is evident that headache as a symptom of serious intracranial events can mimic ear pathology. Therefore, the rare and potentially fatal cranial complications can easily be misdiagnosed, particularly in patient with fever and severe headache in mastoidal area. A typical presentation of symptoms, related to cerebral veins thrombosis include progressive positional headache often accompanied with other neurological signs and symptoms, such as vomiting, dysphasia, stupor, mental disturbance, poor coordination, weakness of the limbs, loss or disturbance of focal sensation, impairment or loss of speech, consciousness disturbance, clinical manifestations of cerebral herniation, and deep coma with cardiac arrest in the worst case. Treatment with heparin is the first choice upon confirmation of sagittal vein thrombosis, even in the presence of small intracerebral hemorrhage. ${ }^{36,37}$ The clinical importance of the sagittal vein thrombosis is the difficulty in making the diagnosis based on the initial clinical and neuro-imaging findings. Clinicians should be aware of this differential diagnosis in a particular patient who has risk factors for venous thrombosis presenting with ear compliant, vestibular symptoms, headache. A brain Computerised Tomography (CT) should be the initial diagnostic resource that would prompt $\mathrm{MRI}$ assessment in cases highly suggestive of isolated vein thrombosis of the posterior fossa. In ideal grounds, a venography (either venous $\mathrm{CT}$ or MRI) should be confirmatory. This form of thrombosis is a differential diagnosis of presumptive rapidly growing cerebellar neoplasms, because they can also have an acute or subacute presentation with a mass effect, perilegional edema, intratumoral bleeding, and compression of the fourth ventricle. ${ }^{38-42}$

Pathologic examination of the atrial mass revealed an organized thrombus. Results of the patient's laboratory tests for possible hypercoagulability showed a protein C deficiency (47\% of normal activity). Warfarin was prescribed to treat the hypercoagulability. At four month follow-up, an echocardiogram showed no evidence of recurrent clot in the patient's right atrium, or headache or neurologic sign and symptom and the patient's protein $\mathrm{C}$ levels had not normalized; therefore, the warfarin was continued.

\section{ACKNOWLEDGMENTS}

We acknowledge the kind efforts made by Dr. Shobeiri (Radiologist), Dr. Salehi (Cardiologist) and nurses at Imam Ali Hospital, Kermanshah University of Medical Sciences, Kermanshah, Iran.

\section{REFERENCES}

1. Poort SR, Rosendaal FR, Reitsma PH, Bertina RM. A common genetic variation in the $3^{\prime}$-untranslated region of the prothrombin gene is associated with elevated plasma prothrombin levels and an increase in venous thrombosis. Blood. 1996 Nov 15;88(10):3698-703.

2. McBane RD 2nd, Tafur A, Wysokinski WE. Acquired and congenital risk factors associated with cerebral venous sinus thrombosis. Thromb Res. 2010 Aug;126(2):81-7.

3. Marlar RA, Mastovich S. Hereditary protein C deficiency: a review of the genetics, clinical presentation, diagnosis and treatment. Blood Coagul Fibrinolysis. 1990 Aug;1(3):319-30.
4. Pescatore SL. Clinical management of protein C deficiency. Expert OpinPharmacother. 2001 Mar;2(3):431- 9.

5. Price DT, Ridker PM. Factor V Leiden mutation and the risks for thromboembolic disease: a clinical prespective. Ann Intern Med. 1997 Nov 15;127(10):895-903.

6. Anderson JA, Weitz JI. Hypercoagulable states. Crit Care Clin. 2011 Oct;27(4):933-52.

7. Pai N, Ghosh K, Shetty S. Acquired and Heritable Thrombophilia in Indian Patients with Pediatric Deep Venous Thrombosis (DVT). ClinApplThrombHemost. 2013 Feb 12. 
8. Risitano AM. Paroxysmal nocturnal hemoglobinuria and the complement system: recent insights and novel anticomplement strategies. AdvExp Med Biol. 2013;735:155-72

9. Qureshi I, Meshaka R, Donohue C, Ali A. Massive pulmonary embolism and thrombophilia. BMJ Case Rep. 2013 Jan 22.

10. Van der Meer FJ, KosterVandenbroucke JP, Briet E, Rosendaal FR. The Leiden Thrombophilia Study (LETS). ThrombHaemost. 1997 Jul;78(1):631-35.

11. Dahlback B, Carlsson M, Svensson PJ. Familial thrombophilia due to a previously unrecognized mechanism characterized by poor anticoagulant response to activated protein C: predication of a cofactor to activated protein C. ProcNatlAcad Sci. 1993 Feb 1;90(3):1004-8.

12. Bertina RM, Koeleman BP, Koster T, Rosendaal FR, Dirven RJ, De Ronde H, et. al. Mutation in blood coagulation factor $\mathrm{V}$ associated with resistance to activated protein C. Nature. 1994 May 5;369(6475):64-7.

13. Seligsohn U, Zivelin A. Thrombophilia as a multigenic disorder. ThrombHaemost. 1997Jul;78(1):297-301.

14. Koeleman BP, Reitsma PH, Allaart CF, Bertina RM. Activated protein $\mathrm{C}$ resistance as an additional risk factor for thrombosis in protein C-deficient families. Blood. 1994 Aug 15;84(4):1031-5.

15. Allaart CF, Poort SR, Rosendaal FR, Reitsma PH, Bertina RM, Briët E. Increased risk of venous thrombosis in carriers of hereditary protein C deficiency defect. Lancet. 1993 Jan 16;341(8838):134-8.

16. Miletich J, Sherman L, Broze G Jr. Absence of thrombosis in subjects with heterozygous protein $\mathrm{C}$ deficiency. N Engl J Med. 1987 Oct 15;317(16):991-6.

17. Svennson PJ, Dahlback B. Resistance to activated protein C as a basis for venous thrombosis. N Engl J Med. $1994 \mathrm{Feb}$ 24;330(8):517-22.

18. Marcos LA, Majid R, Hamzeh N, Mehta N, Escobar M. An acute intracerebral vein thromboses in AIDS with protein C and S deficiency. Int J STD AIDS. 2008 Jan;19(1):59-61.

19. Nagumo K, Fukushima T, Takahashi H, Sakakibara $Y$, Kojima S, Akikusa B. Thyroid crisis and protein $C$ deficiency in a case of superior sagittal sinus thrombosis. Brain Nerve. 2007 Mar;59(3):271-6.

20. Boulos P, Kouroukis C, Blake G. Superior sagittal sinus thrombosis occurring at high altitude associated with protein C deficiency. ActaHaematol. 1999;102(2):104-6.

21. Lefebvre P, Lierneux B, Lenaerts L, Van Maldergem L, Marecaux G, Daune M, et. al. Cerebral venous thrombosis and procoagulant factors- a case study. Angiology. 1998 Jul;49(7):563-71.

22. Confavreux C, Brunet $\mathrm{P}$, Petiot $\mathrm{P}$, Berruyer $\mathrm{M}$, Trillet $\mathrm{M}$, Aimard G. Congenital protein $\mathrm{C}$ deficiency and superior sagittal sinus thrombosis causing isolated intracranial hypertension. J NeurolNeurosurg Psychiatry. 1994 May;57(5):655-7.
23. Weber J, Vida M, Greiner K. Sagittal sinus thrombosis with malignant brain oedema: pathophysiology of cortical veins after decompressivecraniectomy. ActaNeurochir (Wien). 2013 Apr;155(4):651-3.

24. Salunke P, Garg R, Futane S. Acute presentation of sagittal sinus thrombosis following closed head injury without overlying fracture. ActaNeurochir (Wien). 2013 May;155(5):925-6.

25. Katsanos AH, Katsanos KH, Kosmidou M, Giannopoulos S, Kyritsis AP, Tsianos EV. Cerebral sinus venous thrombosis in inflammatory bowel diseases. QJM. 2013 May;106(5):401-13.

26. Okunola PO, Ofovwe GE, Abiodun MT, Azunna CP. Superior sagittal sinus thrombosis complicating typhoid Fever in a teenager. Case Rep Pediatr. 2012;2012:201203.

27. Samanta SK, Mahapatra N, Aich B, Sarkar N, Chatterjee A. An unusual case of transient cortical blindness with sagittal sinus thrombosis in a case of Henoch-Schonleinpurpura. Nepal J Ophthalmol. 2012 Jul-Dec;4(2):333-5.

28. Graff-Radford J, Jones DT, Pruthi RK, Flemming KD. A neurological complication of a uterine fibroid. Neurocrit Care. 2013 Feb;18(1):93-5.

29. Singh G, Kaif M, Deep A, Nakaji P. High-voltage electrical burn of the skull causing thrombosis of the superior sagittal sinus. J ClinNeurosci. 2011 Nov;18(11):1552-4.

30. Huang PH, Su JJ, Lin PH. Iron deficiency anemia - a rare etiology of sinus thrombosis in adults. ActaNeurol Taiwan. 2010 Jun;19(2):125-30.

31. Bruhn HD. Pathophysiology and diagnosis of prethrombosis. Lab Med. 1993;17:164-58.

32. Halbmayer WM, Mannhalter C, Feichtinger C, Rubi K, Fischer M. The prevalence of factor XII deficiency in 103 orally anticoagulated outpatients suffering from recurrent venous and/or arterial thromboembolism. ThrombHaemost. 1992 Sep 7;68(3):285-90.

33. Lodi S, Isa L, Pollini E, Bravo AF, Scalvini A. Defective intrinsic fibrinolytic activity in a patient with severe factor XII-deficiency and myocardial infarction. Scand J Haematol. 1984 Jul;33(1):80-2.

34. Ratnoff OD, Colopy JE. Familial hemorrhagic trait associated with deficiency of clot-promoting fraction of plasma. J Clin Invest. 1955 Apr;34(4):602-13.

35. Ferro JM, Canhao P, Stam J, Bousser MG, Barinagarrementería F; ISCVT investigators. Prognosis of cerebral vein and dural sinus thrombosis : results of the International Study on Cerebral Vein and Dural Sinus Thrombosis (ISCVT). Stroke. 2004 Mar;35(30):664-70.

36. Rousseaux $\mathrm{M}$, Lesoin $\mathrm{F}$, Barbaste $\mathrm{P}$, Jomin $\mathrm{M}$. Infarctuscerebelleux pseudo-tumorald'origineveineuse. Rev Neurol. 1988 Jun;144:209-11.

37. Eng LJ, Longstreth WT Jr, Shaw CM, Eskridge JM, Balhs FH. Cerebellar venous infarction : case report with clinicopathologic correlation. Neurology. 1990 May;40(5):837-8. 
38. Ushiwata I, Saiki I, Murakami T, Kanaya H, Konno J, Wada S. Transverse sinus thrombosis accompanied by intracerebellar hemorrhage: a case report. No ShinkeiGeka. 1989 Jan;17(1):51-5.

39. Nayak AK, Karnad D, Mahajan MV, Shah A, Meisheri YV. Cerebellar venous infarction in chronic suppurative otitis media. A case report with review of four other cases. Stroke. 1994 May;25(5):1058-60.
40. Krespi Y, Gurol ME, Coban O, Tuncay R, Bahar S. Venous infarction of brainstem and cerebellum. J Neuroimaging. 2001 Oct;11(4):425-31.

41. Nakase H, Shin Y, Nakagawa I, Kimura R, Sakaki T. Clinical features of postoperative cerebral venous infarction. ActaNeurochir (Wien). 2005 Jun;147(6):621-6.

42. Masuoka J, Wakamiya T, Mineta T, Takase Y, Kawashima M, Matsushima T. Thrombosis of the superior petrosal vein mimicking brain tumor. Case Report. Neurol Med Chir (Tokyo). 2009 Aug;49(8):359-61. 